\title{
Comparison of repaglinide and metformin monotherapy as an initial therapy in Chinese patients with newly diagnosed type 2 diabetes mellitus
}

\author{
Fu-Sheng Fang, Yan-Ping Gong, Chun-Lin Li, Jian Li, Hui Tian, Wei Huang', \\ Liang-Chen Wang and Lin Li \\ Department of Geriatric Endocrinology, Chinese PLA General Hospital, 28 Fu Xing Road, Beijing 100853, \\ People's Republic of China and 'Department of Endocrinology, Beijing Haidian Hospital, 29 Huangzhuang, \\ Zhongguangcun Street, Beijing 100080, People's Republic of China
}

\author{
Correspondence \\ should be addressed \\ to C-L Li \\ Email \\ Icl301@yeah.net
}

\begin{abstract}
Background: We aimed to compare the effect of repaglinide and metformin monotherapy as an initial therapy in Chinese patients with newly diagnosed type 2 diabetes mellitus (T2DM).

Patients and methods: In this 15-week, open-labelled, parallel-controlled, randomised study, 60 Chinese drug-naive patients with newly diagnosed T2DM were randomised (2:1) to receive repaglinide or metformin monotherapy. Primary endpoint was change in $\mathrm{HbA} 1 \mathrm{c}$ from baseline to the end of the trial. Secondary endpoints included changes in glycaemic variability, insulin sensitivity and $\beta$-cell function.

Results: Patients in both repaglinide and metformin groups achieved significant reductions in $\mathrm{HbA} 1 \mathrm{c}(-1.8 \pm 1.5 \mathrm{vs}-1.6 \pm 1.5 \%)$, FPG (fasting blood glucose) $(-1.7 \pm 1.7 \mathrm{vs}-2.1 \pm 1.7 \mathrm{mmol} / \mathrm{l})$ and $2-\mathrm{h}$ PPG (post-prandial glucose) $(-3.8 \pm 3.1 \mathrm{vs}-3.8 \pm 3.6 \mathrm{mmol} / \mathrm{l})$, with no statistical differences between the groups. Glycaemic variability, glucose infusion rate and $\beta$-cell function were all significantly improved from baseline in the two groups (all $P<0.05$ ), without any statistical differences in the improvement between the groups. Conclusions: Repaglinide and metformin achieved comparable efficacy in improving glycaemic control, reducing glycaemic variability, enhancing insulin sensitivity and ameliorating $\beta$-cell function. Therefore, repaglinide is an optional agent for initial therapy in Chinese patients with newly diagnosed T2DM.
\end{abstract}

\section{Introduction}

Diabetes has become a major public health problem and the prevalence of diabetes among Chinese adults was $9.7 \%$ in 2008 (1). Many interventional studies have reported that diabetic complication was significantly related to dysglycaemia $(2,3,4,5)$. The UK Prospective Diabetes Study (UKPDS) showed that metformin therapy in overweight and obese patients with type 2 diabetes mellitus (T2DM) could reduce HbA1c and significantly decrease the risk of diabetes-related endpoints (6). Therefore, metformin has been suggested to be the drug of first choice after diet failure in obese patients with T2DM (7).
(C) 2014 European Society of Endocrinology Printed in Great Britain
However, the average BMI of Chinese patients with T2DM was about $25 \mathrm{~kg} / \mathrm{m}^{2}$, which was relatively lower than that in people from Western countries (1). The Chinese Diabetes Society guideline suggests metformin as the first-line treatment for overweight/obese patients, while insulin secretagogue could also be used alone in newly diagnosed non-obese patients (8). Repaglinide is a short-acting insulin secretagogue with an excellent anti-hyperglycaemic potency and a lower risk of hypoglycaemia. However, whether repaglinide can be used as an initial therapy in Chinese patients with newly

Published by Bioscientifica Ltd 
diagnosed T2DM is still unconfirmed. A previous study has demonstrated that repaglinide improved firstphase insulin secretion and played a critical role in the regulation of postprandial blood glucose (9). Several studies have demonstrated that repaglinide was similar to metformin with respect to both glycaemic control and cardiovascular risk profile in patients with T2DM $(10,11)$.

The aim of this study was to investigate the feasibility of using repaglinide as an initial therapy in Chinese patients with newly diagnosed T2DM naive to oral antihyperglycaemic agents, by validating the effects of repaglinide on glycaemic control, glycaemic variability, insulin sensitivity and $\beta$-cell function in comparison with metformin monotherapy.

\section{Subjects and methods}

\section{Participants}

Patients aged 20-90 years, diagnosed with T2DM within 6 months, naive to oral anti-hyperglycaemic drugs, with a BMI of $18.5-30 \mathrm{~kg} / \mathrm{m}^{2}$ and with an HbA1c level $<10.0 \%$ were included in this study. Exclusion criteria included T1DM, pregnancy or lactation, impaired hepatic or renal function at screening, decompensated heart failure, unstable angina, alcohol or drug abuse and known or suspected allergy to any trial medications. The study protocol was approved by the Local Ethics Committee and the study was conducted in accordance with the Declaration of Helsinki and Good Clinical Practice. All patients provided written informed consent before participation.

\section{Study design}

This 15-week, open-labelled, parallel-controlled, randomised study was conducted at Chinese PLA General Hospital. Patients were investigated after an overnight fast of at least $10 \mathrm{~h}$. After fasting, blood samples were collected and all patients were served a standard breakfast meal (total energy content $2625 \mathrm{~kJ}$ ) with 34\% fat, 14\% protein and $52 \%$ carbohydrates. Postprandial blood samples were collected at $2 \mathrm{~h}$ after initiation of breakfast. Randomisation was carried out using a computergenerated sequence. The eligible patients were randomised (2:1) to receive thrice-daily monotherapy of repaglinide or metformin. The dose of metformin was $500 \mathrm{mg}$ thrice daily and it remained unchanged through the entire study. Patients receiving repaglinide had an additional 3-week titration period before the dose maintaining period. The starting dose of repaglinide was $0.5 \mathrm{mg}$ for patients with an HbA1c level $<8 \%$ or $1 \mathrm{mg}$ for patients with an HbA1c level $\geq 8 \%$ thrice daily. During the first 3 weeks, repaglinide was uptitrated weekly up to a maximum of $2 \mathrm{mg}$ thrice daily. Repaglinide was titrated by the investigator according to the self-monitored blood glucose of the patient, and the dose could be reduced according to the blood glucose self-monitored by the patients during the following 12 weeks in order to prevent hypoglycaemia based on evaluations from the investigators. Participants were instructed to take repaglinide before meals and metformin with meals. All participants received dietary and exercise advice, and they were asked to follow a recommended controlled-energy diet $(25-35 \mathrm{kcal} / \mathrm{kg}$ per day) and to undertake aerobic activity for at least $30 \mathrm{~min}$ on five occasions per week. There were eight visits in total during the whole 15 -week study period.

\section{Study evaluations}

The primary efficacy endpoint was change in HbA1c from baseline (week 0 ) to week 15 . The secondary efficacy endpoints included changes in FPG, 2-h PPG, glycaemic variability, insulin sensitivity and $\beta$-cell function. Safety and tolerability endpoints included incidences of adverse events (AEs), withdrawals due to AEs, hypoglycaemic events, body weight, physical examination and standard laboratory measures. Pregnancy test was carried out in females of childbearing potential.

Glycaemic variability was evaluated using a 24-h continuous glucose monitoring system (MiniMed, Medtronic, Inc., Northridge, CA, USA) at both baseline and week 15. Data not meeting the manufacturer's standard (correlation of sensor and meter readings not $<0.79$ and a mean absolute difference not more than 28\% (12)) were excluded from the analysis set. A 48-h recording from $0000 \mathrm{~h}$ on day 2 to $0000 \mathrm{~h}$ on day 4 was performed using the CGM device to quantify the mean amplitude of glycaemic excursions (MAGE) and s.D. of mean blood glucose (SDBG) in each patient (13).

Insulin sensitivity expressed as glucose infusion rate (GIR) was assessed by a hyperinsulinaemic euglycaemic clamp procedure (14). The experiments were conducted in a random double-blind fashion. Briefly, insulin (Novolin R, Novo Nordisk) was infused at a rate of $4 \mathrm{mU} / \mathrm{kg}$ per min for $10 \mathrm{~min}$ when clamp was started and maintained at $2 \mathrm{mU} / \mathrm{kg}$ per min for $180 \mathrm{~min}$. Then, 20\% glucose solution was infused (NCA-ST pump, Germany Fresenius Company, Baden-Württemberg, Germany) at a rate 
required to maintain a target plasma glucose concentration of $5.0 \mathrm{mmol} / \mathrm{l}$. Glucose concentrations were monitored at $5 \mathrm{~min}$ intervals using an automated glucose analyser (BIOSEN5030 Glucose Analyser, EKF Diagnostics, Barleben/Magdeburg, Germany), and the glucose infusion was adjusted accordingly. The GIR was calculated based on the amount of glucose infused during the last $30 \mathrm{~min}$ of the clamp during which the GIR was relatively stable.

The function of $\beta$-cell $(\% \beta)$ was evaluated using a homoeostasis model assessment (HOMA 2) (15), with the use of the HOMA Calculator (www.dtu.ox.ac.uk). Plasma glucose was measured using a glucose-oxidase-based approach, and insulin concentration was determined using a RIA Kit (American Diagnostic Products Corporation, Hauppauge, NY, USA) according to the manufacturer's manual.

Each patient was supplied with a calibrated blood glucose meter (ACCU-CHEK Active, Roche) to record self-monitoring blood glucose profiles (SMBG). The 7-point blood glucose was taken before and $120 \mathrm{~min}$ after each meal (breakfast, lunch and dinner), and at bedtime. SMBG was monitored twice a week for the first 3 weeks and once a week for the following 12 weeks in all patients. HbA1c was determined by a chromatography method at baseline and week 15 . The inter-assay coefficient of variation $(\mathrm{CV})$ value of $\mathrm{HbA1c}$ was $0.5-0.9 \%$, and the intra-assay CV value was $1.6-2.3 \%$.

\section{Statistical analyses}

Within-group changes were assessed using the paired t-tests when data were normally distributed; otherwise, non-parametric analysis was applied. Between-group differences were analysed using Student's $t$-test. Categorical data were analysed using the $\chi^{2}$-test to determine univariate differences between the cohorts. The data are presented as the means \pm s.D. for normally distributed continuous variables, median (5th and 95th percentiles) for non-normal continuous variables. $P$ values $<0.05$ were considered statistically significant. The safety analyses set included all patients who received at least one dose of study medication. Hypoglycaemic events (hypoglycaemia symptoms and finger glucose $\leq 2.8 \mathrm{mmol} / \mathrm{l}$ ) were recorded and analysed separately from other AEs.

\section{Results}

\section{Characteristics of subjects}

A total of 71 subjects were screened and 60 participants were randomly assigned to receive either repaglinide
Table 1 Demographic and baseline clinical characteristics at randomisation (means \pm s.D. or median (5th and 95th percentiles)).

\begin{tabular}{|c|c|c|}
\hline & Repaglinide & Metformin \\
\hline$n$ & 40 & 20 \\
\hline Age & $46.4 \pm 10.6$ & $49.7 \pm 10.0$ \\
\hline Gender $(\mathrm{M} / \mathrm{F})$ & $21 / 19$ & $\overline{16 / 4}$ \\
\hline Diabetes duration (months) & $0.8 \pm 1.3$ & $0.4 \pm 0.4$ \\
\hline $\mathrm{BW}(\mathrm{kg})$ & $70.5 \pm 12.0$ & $70.7 \pm 11.2$ \\
\hline BMI $\left(\mathrm{kg} / \mathrm{m}^{2}\right)$ & $26.2 \pm 3.5$ & $25.1 \pm 3.1$ \\
\hline HbA1c (\%) & $8.0 \pm 1.5$ & $7.9 \pm 1.6$ \\
\hline FPG $(\mathrm{mmol} / \mathrm{l})$ & $8.4 \pm 1.9$ & $9.1 \pm 2.6$ \\
\hline 2-h PPG (mmol/l) & $14.4 \pm 3.6$ & $14.2 \pm 4.3$ \\
\hline $\mathrm{SBP}(\mathrm{mmHg})$ & $129.0 \pm 18.7$ & $124.4 \pm 11.8$ \\
\hline $\mathrm{DBP}(\mathrm{mmHg})$ & $77.8 \pm 10.1$ & $78.6 \pm 7.7$ \\
\hline $\mathrm{TC}(\mathrm{mmol} / \mathrm{l})$ & $5.0(3.7,6.4)$ & $4.8(3.5,5.8)$ \\
\hline TG $(\mathrm{mmol} / \mathrm{l})$ & $1.4(0.7,3.9)$ & $1.5(0.9,3.5)$ \\
\hline LDL-C (mmol/l) & $3.1(2.0,3.9)$ & $3.1(1.5,3.8)$ \\
\hline $\mathrm{HDL}-\mathrm{C}(\mathrm{mmol} / \mathrm{l})$ & $1.1(0.8,1.6)$ & $1.1(0.9,1.4)$ \\
\hline
\end{tabular}

$(n=40)$ or metformin $(n=20)$. Of them, 59 patients completed the trial and one patient in the repaglinide group withdrew at the last visit. The demographic and clinical characteristics were well balanced between the repaglinide and metformin groups (Table 1 ).

The dose of repaglinide was initiated at $1.8 \pm$ $0.9 \mathrm{mg} /$ day at baseline, increased to a maximum of $2.1 \pm$ $1.7 \mathrm{mg} /$ day by week 3 and decreased to $1.8 \pm 1.5 \mathrm{mg} /$ day on the last day of treatment. The dose of metformin was $1500 \mathrm{mg} /$ day throughout the study.

\section{Glycaemic control}

At week 15, mean changes in $\mathrm{HbA1c}$ from baseline were $-1.8 \pm 1.5 \%$ in the repaglinide group $(P<0.01)$ and $-1.6 \pm 1.5 \%$ in the metformin group $(P<0.01$, Table 2$)$. No significant difference was found with regard to change in HbA1c level between the two groups $(P=0.739)$. There was no difference in the proportion of patients with an HbA1c level <7.0\% (87.2 vs $90.0 \%, P=0.751)$ and an HbA1c level $<6.5 \%$ (71.8 vs $60.0 \%, P=0.359$ ) between the repaglinide and metformin groups at week 15 .

In patients with an $\mathrm{HbA1c}$ level $<8.0 \%$ at baseline, the changes in HbA1c levels from baseline were $-0.9 \pm 0.7$ and $-0.7 \pm 0.6 \%$ in the repaglinide $(n=25)$ and metformin groups $(n=11)(P=0.456)$ respectively. In patients with an HbA1c level $\geq 8.0 \%$ at baseline, the change in HbA1c from baseline $(-3.4 \pm 0.9$ vs $-2.8 \pm 1.3 \%, P=0.212)$ was also not significantly different between the repaglinide $(n=14)$ and metformin $(n=9)$ groups (Fig. 1C).

Mean changes in FPG and 2-h PPG from baseline were $-1.7 \pm 1.7$ and $-3.8 \pm 3.1 \mathrm{mmol} / 1$ in the repaglinide 
Table 2 Changes in major efficacy endpoints from baseline to the end of the trial.

\begin{tabular}{|c|c|c|c|c|c|}
\hline & \multirow[b]{2}{*}{ Repaglinide } & \multirow[b]{2}{*}{ Metformin } & \multicolumn{2}{|c|}{ Repaglinide-metformin } & \multirow[b]{2}{*}{$P$ value } \\
\hline & & & Mean \pm S.E.M. & $95 \% \mathrm{Cl}$ & \\
\hline \multicolumn{6}{|l|}{ Glycaemic control } \\
\hline $\operatorname{HbA} 1 \mathrm{c}(\%)$ & $-1.8 \pm 1.5$ & $-1.6 \pm 1.5$ & $-0.1 \pm 0.4$ & -0.7 to 0.9 & 0.739 \\
\hline $\mathrm{HbA} 1 \mathrm{c}<7.0 \%$ at end of trial & $34(87.2 \%)$ & $18(90.0 \%)$ & - & - & 0.751 \\
\hline $\mathrm{HbA} 1 \mathrm{c}<6.5 \%$ at end of trial & $28(71.8 \%)$ & $12(60.0 \%)$ & - & - & 0.359 \\
\hline FPG $(\mathrm{mmol} / \mathrm{l})$ & $-1.7 \pm 1.7$ & $-2.1 \pm 1.7$ & $0.4 \pm 0.5$ & -1.4 to 0.5 & 0.362 \\
\hline 2-h PPG (mmol/l) & $-3.8 \pm 3.1$ & $-3.8 \pm 3.6$ & $0.0 \pm 0.9$ & -1.8 to 1.9 & 0.969 \\
\hline \multicolumn{6}{|l|}{ Glycaemic variability } \\
\hline MAGE $(\mathrm{mmol} / \mathrm{l})$ & $-1.4 \pm 2.0$ & $-1.4 \pm 1.6$ & $0.0 \pm 0.5$ & -1.1 to 1.0 & 0.940 \\
\hline SDBG $(\mathrm{mmol} / \mathrm{l})$ & $-0.4 \pm 0.8$ & $-0.5 \pm 0.8$ & $0.1 \pm 0.2$ & -0.4 to 0.6 & 0.675 \\
\hline \multicolumn{6}{|l|}{ Insulin sensitivity } \\
\hline GIR (mg/kg per min) & $+1.2 \pm 3.0$ & $+1.2 \pm 2.3$ & $0.0 \pm 0.9$ & -1.7 to 1.8 & 0.962 \\
\hline \multicolumn{6}{|l|}{$\beta$-cell function } \\
\hline HOMA2 $(\% \beta)$ & $+20.5 \pm 22.9$ & $+17.1 \pm 23.4$ & $3.3 \pm 6.3$ & -16.1 to 9.4 & 0.600 \\
\hline FINS (mU/l) & $+1.3 \pm 4.6$ & $-1.1 \pm 6.4$ & $2.4 \pm 1.5$ & -5.4 to 0.5 & 0.102 \\
\hline 2-h INS (insulin levels) (mU/l) & $+9.9 \pm 28.7$ & $-3.2 \pm 29.1$ & $13.1 \pm 8.1$ & -29.3 to 3.0 & 0.109 \\
\hline \multicolumn{6}{|l|}{ Other } \\
\hline BW $(k g)$ & $0.0 \pm 3.3$ & $-3.0 \pm 2.4$ & $3.1 \pm 0.8$ & -4.7 to -1.4 & 0.001 \\
\hline
\end{tabular}

group (both $P<0.01$, Table 2) and $-2.1 \pm 1.7$ and $-3.8 \pm$ $3.6 \mathrm{mmol} / \mathrm{l}$ in the metformin group (both $P<0.01$ ). No significant difference was found in the above glycaemic parameters between the two groups.

The changes in mean blood glucose (MBG) of 7-point blood glucose and mean fasting blood glucose (FBG) based on SMBG data showed similar trends in the two treatment groups through the entire trial period. For both MBG (repaglinide vs metformin: $8.3 \pm 1.9$ vs $8.3 \pm 2.9 \mathrm{mmol} / \mathrm{l})$ and FBG (7.2 \pm 1.3 vs $7.2 \pm 1.7 \mathrm{mmol} / \mathrm{l})$ at baseline, the values were comparable in the two groups. The values were gradually reduced in the 3-week titration period (with slightly more reduction in the metformin group) and then remained unchanged in the following 12-week dose maintaining period (Fig. 1A and $\mathrm{B})$.

\section{Glycaemic variability}

The mean changes in MAGE from baseline of $4.8 \pm 2.1$ and $4.4 \pm 1.3 \mathrm{mmol} / \mathrm{l} \quad(n=37$ in the repaglinide group and $n=18$ in the metformin group) to week 15 were $-1.4 \pm$ 2.0 in the repaglinide group vs $-1.4 \pm 1.6 \mathrm{mmol} / 1$ in the metformin group (both $P<0.01$ ). The mean changes in SDBG from baseline of $1.8 \pm 0.8$ and $1.7 \pm 0.6 \mathrm{mmol} / \mathrm{l}$ to week 15 were $-0.4 \pm 0.8$ in the repaglinide group vs $-0.5 \pm 0.8 \mathrm{mmol} / \mathrm{l}$ in the metformin group (both $P<0.01)$. For both above glycaemic variability parameters, there was no significant difference between the two treatment groups (Table 2).

\section{Insulin sensitivity}

Hyperinsulinaemic euglycaemic clamp was performed on 46 volunteers of the study participants $(n=31$ in the repaglinide group and $n=15$ in the metformin group). At week 15, the mean changes in the GIR from baseline of $6.1 \pm 2.5$ and $6.4 \pm 2.0 \mathrm{mg} / \mathrm{kg}$ per $\min$ were $+1.2 \pm$ $3.0 \mathrm{mg} / \mathrm{kg}$ per $\min (P=0.035)$ in the repaglinide group and $+1.2 \pm 2.3 \mathrm{mg} / \mathrm{kg}$ per $\min (P=0.053)$ in the metformin group. No significant difference was found between the two groups in GIR changes (Table 2).

\section{$\beta$-cell function}

At week 15 , the mean changes in HOMA2 $(\% \beta)$ from baseline of $34.0 \%(13.0,77.5)$ and $29.8 \%(13.8,85.4)$ were $+20.5 \pm 22.9 \%(P=0.001)$ in the repaglinide group vs $+17.1 \pm 23.4 \%(P=0.020)$ in the metformin group. No significant difference was found between the two groups in $\beta$-cell function changes (Table 2). HOMA2 $(\% \beta)$ was increased in $89.7 \%(35 / 39)$ of patients in the repaglinide group vs $80.0 \%(16 / 20)$ of patients in the metformin group $(P=0.527)$.

The mean changes in FINS from baseline of 8.1 and $8.8 \mathrm{mU} / 1$ were $+1.3 \pm 4.6 \mathrm{mU} / \mathrm{l}(P=0.083)$ in the repaglinide group vs $-1.1 \pm 6.4 \mathrm{mU} / 1(P=0.407)$ in the metformin group. Similarly, at week 15 , the mean changes in 2-h INS from baseline of 39.9 and $35.4 \mathrm{mU} / \mathrm{l}$ were $9.9 \pm 28.7 \mathrm{mU} / \mathrm{l}(P=0.037)$ in the repaglinide group vs $-3.2 \pm 29.1 \mathrm{mU} / \mathrm{l}(P=0.681)$ in the metformin group. 

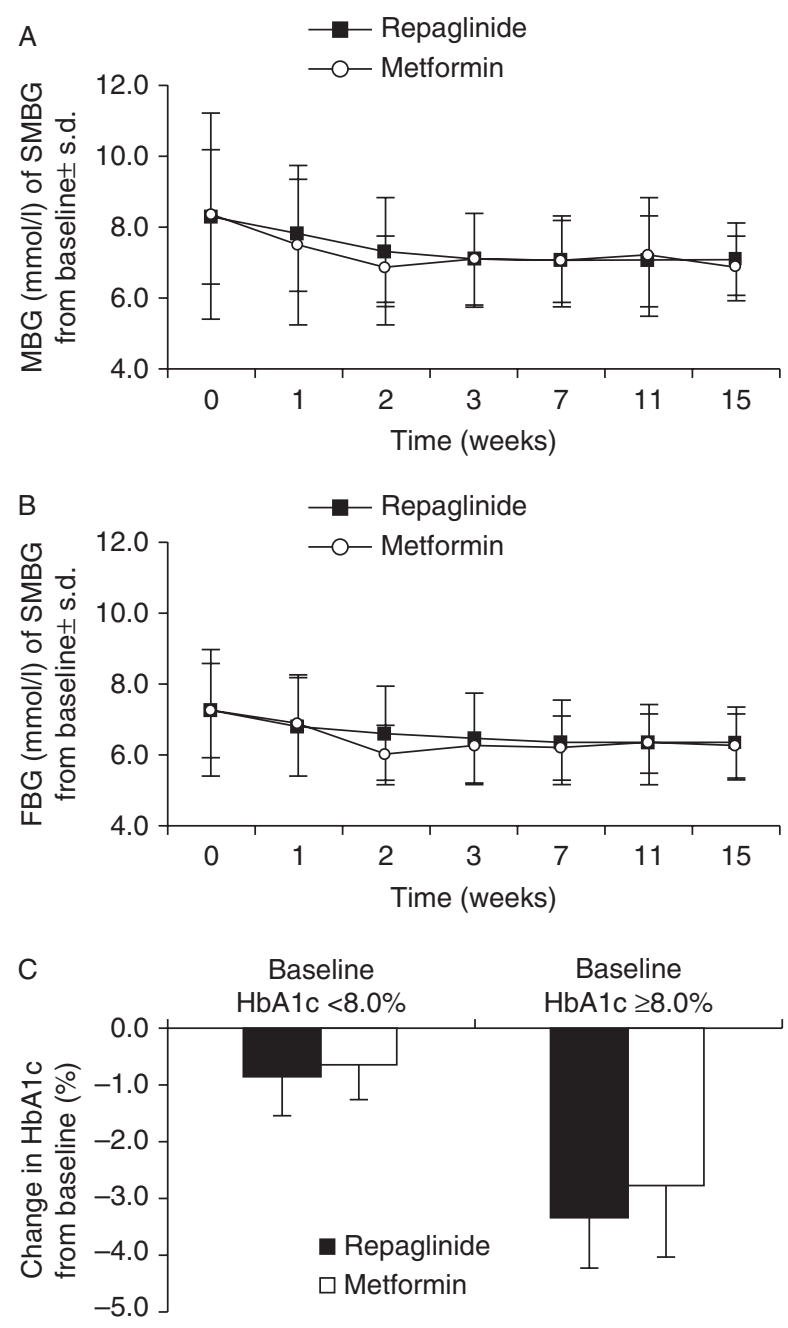

\section{Figure 1}

(A, B and C) Glycaemic control from baseline to the end of the trial.

No significant between-group difference was seen for FINS and 2-h INS.

\section{Safety evaluations}

A total of ten AEs (three reported in the repaglinide group and seven in the metformin group) were recorded in this study. Five AEs were gastrointestinal tract disorders (repaglinide, one subject and metformin, four subjects) and three AEs were respiratory tract infections (repaglinide, one subject and metformin, two subjects). One subject in the repaglinide group suffered from sunstroke and recovered soon after rest, and one female subject in the metformin group was diagnosed as having uterine fibroids. No major hypoglycaemic event (requiring assistance or hospital admission) was reported in both treatment groups during the entire period of the study. For minor hypoglycaemic events ( $\mathrm{BG} \leq 2.8 \mathrm{mmol} / \mathrm{l}$ ) or symptomatic hypoglycaemic events, 12 were reported in the repaglinide group (two hypoglycaemic events in two subjects and ten symptomatic hypoglycaemic events in nine subjects) and none in the metformin group. At week 15 , the changes in body weight were $0.0 \pm 3.3 \mathrm{~kg}$ in the repaglinide group $(P>0.05)$ and $-3.0 \pm 2.4 \mathrm{~kg}$ in the metformin group $(P<0.01)$. None of the subjects in either treatment groups reported abnormal findings in physical examination and laboratory measurements.

\section{Discussion}

This was a 15-week, open-labelled, parallel-controlled, randomised study to compare the effectiveness of repaglinide and metformin monotherapy as an initial therapy in Chinese patients with newly diagnosed T2DM. HbA1c, glycaemic variability, GIR and $\beta$-cell function were all significantly improved from baseline by both treatments, without any difference between the groups. Our study provided evidence that repaglinide might have a similar effect on patients with newly diagnosed T2DM in an initial 15-week therapy when compared with metformin.

Risk of developing microvascular complications was intimately related to the glycaemic control of diabetic subjects, which was confirmed by the Diabetes Control and Complications Trial (DCCT) in T1DM and the UKPDS in T2DM $(16,17)$. Due to robust evidence, current international guidelines recommend metformin as the only first-line oral anti-hyperglycaemic agent for patients with newly diagnosed T2DM $(7,18)$. As gastrointestinal complications occur in more than $20 \%$ of the patients using metformin $(19,20)$, other anti-hyperglycaemic agents are considered as substitutes for the initial pharmacological therapy for those with contraindications to metformin. In this study, repaglinide and metformin had similar effects on HbA1c, which was in accordance with previous studies $(10,11)$. At the end of the trial, $87.2 \%$ of patients in the repaglinide group and $90.0 \%$ of patients in the metformin group achieved HbA1c $<7.0 \%$. Besides its effect on $\mathrm{HbA1c}$, we also found that repaglinide exhibited a similar effect on FPG, 2-h PPG, glycaemic variability, insulin resistance and $\beta$-cell function when compared with metformin. Therefore, our study showed that repaglinide could be an optional drug for initial therapy in newly diagnosed T2DM patients, especially for those with contraindications to metformin. 
In Chinese patients with T2DM, postprandial glucose was a predominant contributor to excess hyperglycaemia (21). Although repaglinide can markedly improve postprandial glucose control (10), a better effect of repaglinide when compared with metformin in reducing 2-h PPG and glycaemic variability was not found in the study, which was similar to another study reported by Lund et al. (22). The failure to detect the superiority of repaglinide could be attributed to the following aspects: first, the study subjects were patients with newly diagnosed T2DM who might have a relatively better pancreatic $\beta$-cell function and a more sensitive response to anti-hyperglycaemic agents. Although HbA1c decreased markedly, the dose of repaglinide used in this study was relatively lower when compared with other studies $(10,23)$. Furthermore, diet control was usually strictly followed by patients with newly diagnosed T2DM (24), which may contribute to glycaemic control. Based on diet control, metformin was associated with balanced improvements in 2-h PPG and glycaemic variability when compared with repaglinide. In addition, neither major nor minor hypoglycaemic events were reported in the metformin group. As glycaemic variability assessed by MAGE was calculated as the variation around MBG by summating the absolute rises or falls encountered in a day, patients treated with metformin might have had relatively lower variability due to no hypoglycaemia. Lund et al. (22) compared the effect of metformin vs repaglinide on postprandial metabolism in non-obese T2DM patients, showing significantly higher levels of postprandial insulin and $\mathrm{C}$-peptide with repaglinide vs metformin. There is no statistical difference in 2-h insulin levels between repaglinide and metformin in this study. However, 2-h insulin increased significantly from baseline in the repaglinide group, and changed slightly in the metformin group. The trend is consistent with the study reported by Lund et al. (22). The lack of statistical difference in 2-h insulin between the two treatments in this study might be attributed to a high s.D. and a small sample size.

This study suggested that repaglinide and metformin could be used to reduce glycaemic variability in patients with newly diagnosed T2DM. Not only sustained hyperglycaemia but also acute glycaemic variability contributed to diabetic complications (25). Acute glycaemic variability was shown to be more deleterious than sustained high level of glucose to endothelial cells and human kidney proximal tubule cells $(26,27)$. Glycaemic variability has been a therapeutic target of several clinical studies and several anti-diabetic agents have been confirmed to reduce variability in glycaemia $(28,29,30)$. Our data supported the effectiveness of repaglinide and metformin in glycaemic variability control in patients with T2DM.

Impaired pancreatic $\beta$-cell function and insulin resistance were characteristics of T2DM (31). In this study, we found a similar improvement in $\beta$-cell function, as measured by HOMA, in the repaglinide and metformin groups. The amelioration of $\beta$-cell function was mainly related to the elimination of glucotoxicity after treatment in both groups. Our finding is in accordance with one study reporting that repaglinide improved $\beta$-cell function and mimicked the normal postprandial early-phase insulin secretion in patients with T2DM (9) and agrees with other studies showing that repaglinide enhanced $\beta$-cell function more effectively than traditional sulphonylureas $(11,32)$. However, the HOMA model was used under conditions of pharmacologically induced changes in glucose and in particular insulin metabolism such as treatment with an insulin secretagogue. The HOMA model typically pertains to an untreated person and the use of glucose-lowering drugs may violate the basic assumptions in the model. Therefore, we should also note that an apparent increased HOMA $(\% \beta)$ after short-term therapy may be due to the pharmacology of repaglinide or improvement in glycaemic control, and this does not mean a 'healthier' $\beta$-cell, which had been demonstrated in the study by Kahn et al. (33). The reduction in insulin resistance, as evaluated by the GIR (34), was comparable in both groups. It has been reported that certain therapeutic interventions lead to enhanced insulin sensitivity and improved $\beta$-cell function (35). Metformin was also shown to be effective in reducing insulin resistance, and similarly, the reduction in insulin resistance by repaglinide could be attributed to its efficacy in glycaemic control.

Open-label design in this study might bias the results. Further limitations include a short study period and a small sample size. Insulin secretagogues may lose efficacy with time and duration of diabetes, so this study is preliminary and a larger sample size and a longer duration are required to further verify the conclusion. In this study, repaglinide was titrated up to a maximum dose of $6 \mathrm{mg} /$ day, while metformin was at a fixed dose of $1500 \mathrm{mg} /$ day. This might have influenced the study results, though the comparative efficacy was observed in this study. However, the mean dose of repaglinide of about $2 \mathrm{mg} /$ day at the end of trial is much lower than the maximum allowed dose of $6 \mathrm{mg} /$ day. In addition, metformin was commonly used up to a dose of $1500 \mathrm{mg} /$ day in real world practice and trials in China (36), rather than being titrated to a dose of $2000 \mathrm{mg} /$ day as recommended by the guidelines. Metformin was initiated 
at a dose of $1500 \mathrm{mg} /$ day without titration, which may increase the frequency of gastrointestinal AEs in this study. Lastly, the limited accuracy of the CGM device should be concerned, especially the relatively weak stability in the first day after measurement. Therefore, we quantify glycaemic variability using the intermediate 48-h CGM recording in the study.

In conclusion, in addition to its efficacy in glycaemic control, repaglinide showed comparable effectiveness to metformin in reducing glycaemic variability, enhancing insulin sensitivity and ameliorating $\beta$-cell function. This study provided preliminary evidence that repaglinide could be used as an initial therapy in part of Chinese patients with newly diagnosed T2DM who have contraindications to metformin.

\section{Declaration of interest}

The authors declare that there is no conflict of interest that could be perceived as prejudicing the impartiality of the research reported.

\section{Funding}

This study was supported by an unrestricted educational grant from Novo Nordisk Pharmaceuticals, China. We accept full responsibility for design, statistical analysis, interpretation of results and the subsequent writing-up of this study. Trial number: NCT00832481, ClinicalTrials.gov.

\section{References}

1 Yang W, Lu J, Weng J, Jia W, Ji L, Xiao J, Shan Z, Liu J, Tian H, Ji Q et al. Prevalence of diabetes among men and women in China. New England Journal of Medicine 2010362 1090-1101. (doi:10.1056/ NEJMoa0908292)

2 DCCT. The effect of intensive treatment of diabetes on the development and progression of long-term complications in insulin-dependent diabetes mellitus. New England Journal of Medicine 1993329 977-986. (doi:10.1056/NEJM199309303291401)

3 Stratton IM, Adler AI, Neil HA, Matthews DR, Manley SE, Cull CA, Hadden D, Turner RC \& Holman RR. Association of glycaemia with macrovascular and microvascular complications of type 2 diabetes (UKPDS 35): prospective observational study. BMJ 2000321 405-412. (doi:10.1136/bmj.321.7258.405)

4 Patel A, MacMahon S, Chalmers J, Neal B, Billot L, Woodward M, Marre M, Cooper M, Glasziou P, Grobbee D et al. Intensive blood glucose control and vascular outcomes in patients with type 2 diabetes. New England Journal of Medicine 2008358 2560-2572. (doi:10.1056/ NEJMicm066227)

5 Gaede P, Lund-Andersen H, Parving HH \& Pedersen O. Effect of a multifactorial intervention on mortality in type 2 diabetes. New England Journal of Medicine 2008358 580-591. (doi:10.1056/NEJMoa0706245)

6 UKPDS. Effect of intensive blood-glucose control with metformin on complications in overweight patients with type 2 diabetes (UKPDS 34). UK Prospective Diabetes Study (UKPDS) Group. Lancet 1998352 854-865. (doi:10.1016/S0140-6736(98)07037-8)

7 American Diabetes Association. Standards of medical care in diabetes2014. Diabetes Care 201437 (Suppl 1) S14-S80. (doi:10.2337/dc14S014)
8 Chinese Diabetes Society. Chiese guideline for the treatment of type 2 diabetes, 2010. Chinese Jounal of the Frontiers of Medical Science 20113 54-109. (doi:10.3969/j.issn.1674-7372.2011.06.014)

9 Li Y, Xu L, Shen J, Ran J, Zhang Y, Wang M, Yan L, Cheng H \& Fu Z. Effects of short-term therapy with different insulin secretagogues on glucose metabolism, lipid parameters and oxidative stress in newly diagnosed type 2 diabetes mellitus. Diabetes Research and Clinical Practice 201088 42-47. (doi:10.1016/j.diabres.2009.12.017)

10 Derosa G, Mugellini A, Ciccarelli L, Crescenzi G \& Fogari R. Comparison of glycaemic control and cardiovascular risk profile in patients with type 2 diabetes during treatment with either repaglinide or metformin. Diabetes Research and Clinical Practice 200360 161-169. (doi:10.1016/S0168-8227(03)00057-3)

11 Lund SS, Tarnow L, Stehouwer CD, Schalkwijk CG, Frandsen M, Smidt UM, Pedersen O, Parving HH \& Vaag A. Targeting hyperglycaemia with either metformin or repaglinide in non-obese patients with type 2 diabetes: results from a randomized crossover trial. Diabetes, Obesity \& Metabolism 20079 394-407. (doi:10.1111/j. 1463-1326.2007.00713.x)

12 Mastrototaro JJ. The Minimed continuous glucose monitoring system (CGMS). Journal of Pediatric Endocrinology \& Metabolism 199912 751-758.

13 Rausch JR. Measures of glycemic variability and links with psychological functioning. Current Diabetes Reports 201010 415-421. (doi:10.1007/s11892-010-0152-0)

14 DeFronzo RA, Tobin JD \& Andres R. Glucose clamp technique: a method for quantifying insulin secretion and resistance. American Journal of Physiology 1979237 E214-E223.

15 Wallace TM, Levy JC \& Matthews DR. Use and abuse of HOMA modeling. Diabetes Care 200427 1487-1495. (doi:10.2337/diacare. 27.6.1487)

16 Murray P, Chune GW \& Raghavan VA. Legacy effects from DCCT and UKPDS: what they mean and implications for future diabetes trials. Current Atherosclerosis Reports 201012 432-439. (doi:10.1007/ s11883-010-0128-1)

17 Albers JW, Herman WH, Pop-Busui R, Feldman EL, Martin CL, Cleary PA, Waberski BH \& Lachin JM. Effect of prior intensive insulin treatment during the Diabetes Control and Complications Trial (DCCT) on peripheral neuropathy in type 1 diabetes during the Epidemiology of Diabetes Interventions and Complications (EDIC) Study. Diabetes Care 201033 1090-1096. (doi:10.2337/dc09-1941)

18 Inzucchi SE, Bergenstal RM, Buse JB, Diamant M, Ferrannini E, Nauck M, Peters AL, Tsapas A, Wender R \& Matthews DR. Management of hyperglycaemia in type 2 diabetes: a patient-centered approach. Position statement of the American Diabetes Association (ADA) and the European Association for the Study of Diabetes (EASD). Diabetologia 201255 1577-1596. (doi:10.1007/s00125-012-2534-0)

19 Okayasu S, Kitaichi K, Hori A, Suwa T, Horikawa Y, Yamamoto M, Takeda J \& Itoh Y. The evaluation of risk factors associated with adverse drug reactions by metformin in type 2 diabetes mellitus. Biological \& Pharmaceutical Bulletin 201235 933-937. (doi:10.1248/bpb.35.933)

20 Ali S \& Fonseca V. Overview of metformin: special focus on metformin extended release. Expert Opinion on Pharmacotherapy 201213 1797-1805. (doi:10.1517/14656566.2012.705829)

21 Wang JS, Tu ST, Lee IT, Lin SD, Lin SY, Su SL, Lee WJ \& Sheu WH. Contribution of postprandial glucose to excess hyperglycaemia in Asian type 2 diabetic patients using continuous glucose monitoring. Diabetes/Metabolism Research and Reviews 201127 79-84. (doi:10.1002/ dmrr.1149)

22 Lund SS, Tarnow L, Frandsen M, Smidt UM, Pedersen O, Parving HH \& Vaag AA. Impact of metformin versus the prandial insulin secretagogue, repaglinide, on fasting and postprandial glucose and lipid responses in non-obese patients with type 2 diabetes. European Journal of Endocrinology 2008158 35-46. (doi:10.1530/EJE-07-0500)

23 Papa G, Fedele V, Rizzo MR, Fioravanti M, Leotta C, Solerte SB, Purrello F \& Paolisso G. Safety of type 2 diabetes treatment with 
repaglinide compared with glibenclamide in elderly people: a randomized, open-label, two-period, cross-over trial. Diabetes Care 2006 29 1918-1920. (doi:10.2337/dc05-2495)

24 Andrews RC, Cooper AR, Montgomery AA, Norcross AJ, Peters TJ, Sharp DJ, Jackson N, Fitzsimons K, Bright J, Coulman Ket al. Diet or diet plus physical activity versus usual care in patients with newly diagnosed type 2 diabetes: the Early ACTID randomised controlled trial. Lancet 2011378 129-139. (doi:10.1016/S0140-6736(11)60442-X)

25 Kilpatrick ES, Rigby AS \& Atkin SL. Effect of glucose variability on the long-term risk of microvascular complications in type 1 diabetes. Diabetes Care 200932 1901-1903. (doi:10.2337/dc09-0109)

26 Risso A, Mercuri F, Quagliaro L, Damante G \& Ceriello A. Intermittent high glucose enhances apoptosis in human umbilical vein endothelial cells in culture. American Journal of Physiology. Endocrinology and Metabolism 2001281 E924-E930.

27 Jones SC, Saunders HJ, Qi W \& Pollock CA. Intermittent high glucose enhances cell growth and collagen synthesis in cultured human tubulointerstitial cells. Diabetologia 199942 1113-1119. (doi:10.1007/ s001250051279)

28 Bao YQ, Zhou J, Zhou M, Cheng YJ, Lu W, Pan XP, Tang JL, Lu HJ \& Jia WP. Glipizide controlled-release tablets, with or without acarbose, improve glycaemic variability in newly diagnosed type 2 diabetes. Clinical and Experimental Pharmacology \& Physiology 201037 564-568. (doi:10.1111/j.1440-1681.2010.05361.x)

29 White NH, Chase HP, Arslanian S \& Tamborlane WV. Comparison of glycemic variability associated with insulin glargine and intermediateacting insulin when used as the basal component of multiple daily injections for adolescents with type 1 diabetes. Diabetes Care 200932 387-393. (doi:10.2337/dc08-0800)
30 McCall AL, Cox DJ, Brodows R, Crean J, Johns D \& Kovatchev B. Reduced daily risk of glycemic variability: comparison of exenatide with insulin glargine. Diabetes Technology \& Therapeutics 200911 339-344. (doi:10.1089/dia.2008.0107)

31 Zethelius B, Berglund L, Hanni A \& Berne C. The interaction between impaired acute insulin response and insulin resistance predict type 2 diabetes and impairment of fasting glucose: report from a 20-year follow-up in the Uppsala Longitudinal Study of Adult Men - ULSAM. Upsala Journal of Medical Sciences 2008113 117-130. (doi:10.3109/ 2000-1967-226)

32 Wu CZ, Pei D, Hsieh AT, Wang K, Lin JD, Lee LH, Chu YM, Hsiao FC, Pei C \& Hsia TL. Comparison of insulin sensitivity, glucose sensitivity, and first phase insulin secretion in patients treated with repaglinide or gliclazide. Archives of Pharmacal Research 201033 411-416. (doi:10.1007/s12272-010-0310-6)

33 Kahn SE, Haffner SM, Heise MA, Herman WH, Holman RR, Jones NP, Kravitz BG, Lachin JM, O'Neill MC, Zinman B et al. Glycemic durability of rosiglitazone, metformin, or glyburide monotherapy. New England Journal of Medicine 2006355 2427-2443. (doi:10.1056/NEJMoa066224)

34 Matsuda M. Measuring and estimating insulin resistance in clinical and research settings. Nutrition, Metabolism, and Cardiovascular Diseases 201020 79-86. (doi:10.1016/j.numecd.2009.07.007)

35 DeFronzo RA. Insulin resistance, lipotoxicity, type 2 diabetes and atherosclerosis: the missing links. The Claude Bernard Lecture 2009. Diabetologia 201053 1270-1287. (doi:10.1007/s00125-010-1684-1)

36 Yang W, Liu J, Shan Z, Tian H, Zhou Z, Ji Q, Weng J, Jia W, Lu J, Liu J et al. Acarbose compared with metformin as initial therapy in patients with newly diagnosed type 2 diabetes: an open-label, non-inferiority randomised trial. Lancet. Diabetes \& Endocrinology 20142 46-55. (doi:10.1016/S2213-8587(13)70021-4)

Received 18 January 2014

Revised version received 1 April 2014

Accepted 2 April 2014 